\title{
Overcooling of office buildings in Malaysia
}

\section{Nurul Zahirah Mokhtar Azizi ${ }^{{ }^{*}}$, Nazirah Zainul Abidin ${ }^{2}$, Nurul Sakina Mokhtar Azizi ${ }^{3}$, Nasyairi Mat Nasir ${ }^{4}$}

\author{
1, 2, 3 Universiti Sains Malaysia, Penang, Malaysia \\ ${ }^{1}$ Heriot-Watt University Malaysia, Putrajaya, Malaysia \\ ${ }^{4}$ Universiti Teknologi MARA, Shah Alam, Malaysia
}

\section{Key Words \\ Office building \\ Energy efficiency \\ Overcooling \\ Thermal comfort}

Received: 15 April 2017

Accepted: 13 June 2017

Published: 30 June 2017

\begin{abstract}
As global warming becomes more substantial, office buildings in Malaysia widely use air conditioning as an active design solution to cool the building. However, thermal comfort is often a problem in many offices using a centralized air conditioner where occupants complain that the indoor climate is too cold. The overcooling effect is a result of over-specification of air conditioning systems, which lead to inefficient energy consumption and thermal discomfort. This paper identibies and explains the underlying causes of over-specification of air conditioning systems. The investigation focuses on understanding the factors affecting active design decisions. A total of 39 construction consultants participated in face-to-face interviews that were conducted in individual and group meetings. Research findings revealed that the problem could be attributed to the practice of quick solutions, resistance from design consultants, a 'bigger is better' mentality, unsupportive fee structures, and poor testing and commissioning practices. The highest contributing factor is the resistance of design consultants to change and consider new solutions that break away from customary practices. The research findings provide useful information to policy makers regarding the over-cooling phenomenon in Malaysia and highlight the importance of energy efficient regulations to be imposed.
\end{abstract}

\section{INTRODUCTION}

Urbanization has touched all parts of the world with more and more people choosing to live in urban areas (Alyami and Yacine, 2012). While development has surely benefitted the human population in various ways, it has costed rapid consumption of energy sources and high carbon emission, which has resulted to climate change (Tisdell, 2008; Lindner et al., 2010). It is predicted that the effects of climate change will cause heatwaves to occur more frequently and intensely, and will largely afflict metropolitan areas that are not designed to adapt to these conditions (Luber and Michael, 2008). Energy source such as burning of fossil fuels release high carbon dioxide content in the atmosphere and acts like a layer of glass that prevents heat from releasing into space. This phenomenon is called the greenhouse effect that contributes to global warming (Omer, 2008). With warmer climate conditions, this means that higher energy levels are needed for heating and cooling buildings (Wang et al., 2010).

Electricity is the basic need of all living beings. In response to the environmental situa-

\footnotetext{
${ }^{*}$ Corresponding author: Nurul Zahirah Mokhtar Azizi

†Email: n.mokhtar_azizi@hw.ac.uk
} 
tion, countries across the globe have introduced policies and programs to promote energy efficiency (United Nations Development Programme (UNDP), 2009). Energy used to heat and cool spaces is one of the fundamental aspects of a building design to ensure appropriate level thermal comfort. Past research has shown that buildings consumed a sum of $60 \%$ of energy use of which $26 \%$ are from commercial buildings alone. Air-conditioning in commercial buildings typically account for $44 \%$ of their energy consumption, which is nearly half of the total building energy (Baker and Koen, 2003). To bring down the level of energy consumption, efficient use of air-conditioning is utmost important.

In USA for example, the Energy Policy Act was introduced in 2005 to endorse energy efficient building designs that reduced the average energy consumption while also minimizing environmental impact and improving the building's thermal comfort (National Institute of Building Sciences (NIBS), 2008). A post evaluation of building helped to ensure building occupants' comfort by addressing their needs in an energy efficient design. However, research indicates that majority of occupants in office spaces feel that the indoor environment is often too cold due to air-conditioning systems (Ng and Zainal, 2013).

Abbaszadeh et al. (2006) informed that even occupants in green buildings found that the indoor environment quality was less than contenting as it did not meet their desired comfort level. It was found that many buildings fall far short from the recommended acceptable standards set out for thermal comfort (Huizenga et al., 2006).

The paper focuses on the problem of overcooling in office buildings and explores the underlying reasons behind the situation. These are interpreted in terms of the rational choice theory to explain the decision behavior of building designers when specifying a cooling system as this is where the highest energy consumption is found for buildings in tropical countries. The findings of the study contribute to the construction body of knowledge by revealing explanations that elucidate the common issue of overcool office buildings. The implications of the study are that improvements can be made to the design specification process in construction projects.

\section{LITERATURE REVIEW}

The issue of overcooling in office spaces is a common problem observed by many organisations worldwide (Boshoff, 2016; OSHREP, 2016). Post Occupancy Evaluation (POE) research indicate that a large majority of employees are generally unsatisfied with the thermal comfort level of their office. In many cases, the office is either too hot or too cold (Ng and Zainal, 2013). With the improved standard of living today, people tend to expect better comfort levels and have gotten used to having this provided by an air conditioning system in warm climate areas (Zhang and Siu, 2013). Tropical countries widely use air conditioning systems in buildings to cool the indoor environment. It was found that people living in the tropics showed less tolerance to warmth in air conditioned offices as compared to cold climate countries (de Dear and Marc, 1994). Thus, office buildings are usually designed with high cooling loads to cater for the demand. Air conditioners with high cooling loads consume a lot of energy that result to high electricity costs during the building operation (Albadi and Ehab, 2008).

On average, air conditioning systems account for $70 \%$ of the yearly building energy consumption (Ahmad and Abd Aziz, 2011; Suziyana et al., 2013). With such high consumption, air conditioned offices become inefficient in terms of energy. In addition, air conditioners produce Hydrofluorocarbons (HFCs), a potent greenhouse gas that contribute significantly to global warming. With the rising demand for air conditioners, this will mean higher emissions of HFCs, which lead to a compelling danger of global warming phenomena (McSweeney, 2015). 
It was discovered that one of the prevalent factors undermining energy efficiency was the over-specification of Heating, Ventilation and Air Conditioning (HVAC) systems in buildings. A study identified that $15 \%$ or more of HVAC systems in the UK were oversized and caused excessive energy consumption (Sorrell, 2003). Over-specification or oversizing of HVAC systems were the result of lack of integration in active and passive building design. It was reinforced by the need for engineers to reduce their legal liability and to allow future potential changes in the building use in future (Sorrell, 2003). Due to lack of time allocation for a detailed specification and design development, more of the detailed design works were passed to specialist contractors (Lovins, 1992). This means that the HVAC system is specified in the absence of a coordinated design work and incomplete information on the building performance, electrical load and passive heat generation. As a safety measure, specialist contractors typically add a safety margin on the ideal equipment size to ensure the HVAC equipment can accommodate any changes in the design requirements (Sorrell, 2003). Hence, buildings end up with specification for bigger-than-necessary cooling systems that are energy inefficient and environmentally hazardous.

Aside from being wasteful from an energy perspective, overcooling also leads to thermal discomfort, which causes loss of worker productivity especially in typing activity (Kosonen and Tan, 2004, Lan et al., 2011a). Studies have found that the thermal environment of an office space exerts direct influence on employee productivity without influencing their general health (Ardyanfitri and Ratri, 2016; El-Ghalayini, 2016; Lan et al., 2011b). Research have shown that employee productivity improves in an office space with good indoor environment quality which includes the factor of room temperature (Chua et al., 2016). A summary of the literature findings is shown in Figure 1.

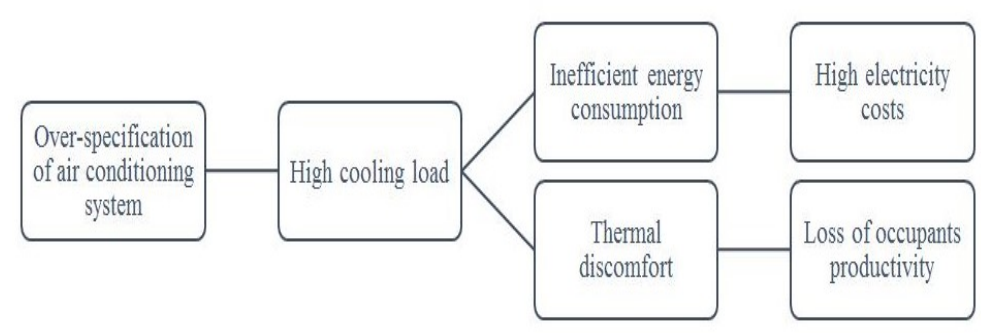

FIGURE 1. Effects of over-specification of air conditioning system

The arguments above confirm that the problem of overcooling from oversized air conditioning systems present many problems that could otherwise be avoided with the right specification during building design. While the need to correctly specify the building cooling load is evident, it is not clear why over-specification occurs. Literature findings substantiating this problem can be traced back from as early as 1990s and yet, the same issue is still discussed in more recent research.

The principle of rational choice theory states that people make prudent and logical decisions that provide the biggest benefit or satisfaction to themselves. The theory postulates that any action can be explained by reasons in the individual's mind. A second postulate is that the reasons are motivated by the consequences of their actions (Boudon, 2009). Lovett (2006) viewed rational choice theory as an approach to provide causal explanations. He described the discrete purposeful actor assumption, which maintains that actions are performed purposefully based on consideration of possible courses of action.

Following this principle, the act of over-specifying active design can be explained through 
the rational choice theory with a number of underlying reasons. This paper identifies and explains the underlying causes of over-specification in office air-conditioning systems.

\section{METHODOLOGY}

The research intends to answer the question of why over-specification of air conditioning occurs. Hence, a qualitative approach using in-depth interviews was justified for conducting the study (Creswell, 2012). As the enquiry aimed to understand the human thought process in decision-making, a human instrument was found to be most suitable to understand a particular context by deriving meaning from human experience (Ary et al., 2013; Lincoln and Egon, 1985). Verbal data was used to analyze professional experiences and knowledge because practitioners often have an extensive implicit knowledge about their practices with specific issues or target groups which can be made explicit in interviews (Flick, 2014). Purposive sampling was used to identify research participants from construction organizations that fit the purpose of the study. The samples were selected from those professionals in construction industry with more than 10 years of experience (Bryman, 2008). A total of 39 construction players were approached in a semi-structured interview session (Fig. 2). The interviewees were asked to state their opinion on the problem of overcooling in office spaces in Malaysia and explain how the role of active design was concerned. The interview results were recorded on tape and noted down using an aidememoir during the meeting. The results of the interview were transcribed using the Microsoft Word software and transferred into the NVIVO software for thematic analysis. Thematic analysis allowed the rich data to be deciphered using codes and convened into relevant themes. The research area focused exclusively on the Klang Valley region in Malaysia and the information presented reflect the findings for the Malaysian construction industry only.

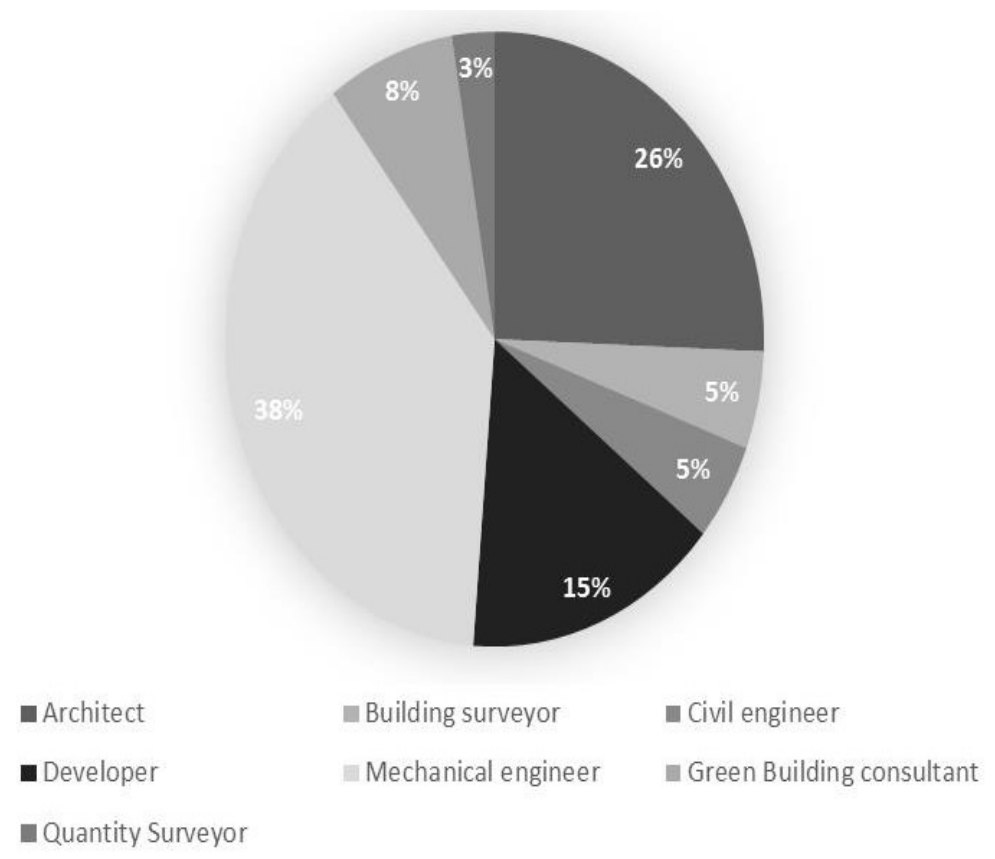

FIGURE 2 . Distribution of interview participants 


\section{RESULTS}

The interview yielded five underlying causes of over-specification in cooling system, which renders inefficient energy consumption over the building life. Figure 3 presents the findings of the empirical enquiry in five themes.

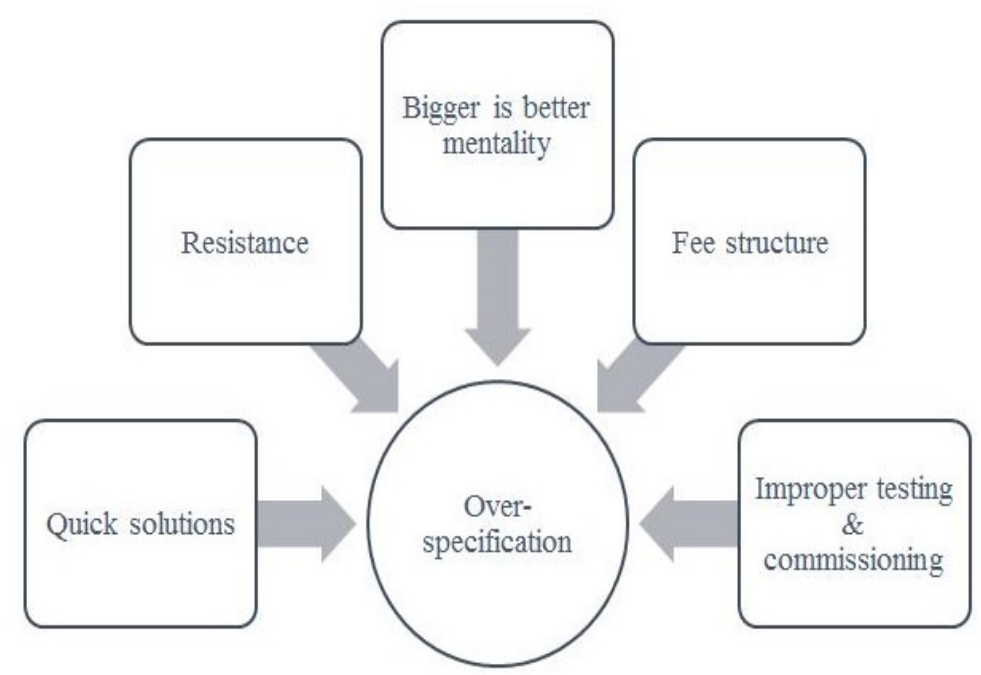

FIGURE 3 . Causes of over-specification in cooling system

\section{Quick Solutions}

It is the role of M\&E engineers to provide active design solutions for the building in the interest of the client. The correct way to select an appropriate air-conditioner for a building is to calculate the building cooling load and select one that is sized to that load. However, decisions made are usually influenced by availability and representativeness of heuristic. Heuristic is the decision-making technique based on past experiences that speed up the decision-making process via mental shortcuts (Cherry, 2014). Some examples include using a rule of thumb, making an educated guess, stereotyping, or common sense. People tend to make decisions based on readily available knowledge. People with more experience in hand use more mental shortcuts than those with less, as their brain can quickly generate a response to a familiar situation or similar problem based on past experience.

Almost $90 \%$ of interviewees reported that in actual practice, mechanical engineers commonly follow the general rule of thumb that determines the size of air conditioning by total square feet of the building footprint alone as this is the fastest and easiest method. While it works, it is not accurate and certainly does not take into consideration factors such as the architectural design efficiency and overall thermal transfer value of building elements. That being the case, the air-conditioning system installed is decided in isolation of the contributing factors to building cooling load. Thus, the architectural design and mechanical design are not integrated, and do not reap the benefits from the other.

"They may have specified, let's say more expensive glass, but they never benefitted from the fact that they could have downsized the cooling system" (G02).

For green buildings, energy efficiency is key. Hence, using this rule of thumb approach does not help in achieving the required level of energy efficiency. On the contrary, it adds on unnecessary cost for installing an oversized cooling system befitting the building square feet area, when in fact the actual cooling load is much less than what would normally be anticipated. While the rule of thumb provides a helpful guideline for sizing air conditioning, it is not based on the actual cooling load of the building that considers all sustainable 
architecture features incorporated by the architect such as low energy lighting and glazing features, which reduces the required size of cooling system.

"The mechanical engineer, who has to sign off on the cooling system, they are often reluctant to downsize the cooling system. Because they have this rule of thumb that says okay, for this big a building I need this big a chiller" (G03).

\section{Resistance}

All 39 interviewees agreed that resistance from design consultants to adopt energy efficient solutions is a common problem. Many engineers come on board a project with their own experiences from other projects. Hence, they incline to use solutions that have been well-tried over many years and follow solutions they know and are confident with. The natural reaction of mechanical engineers is to oppose new design solutions that they are not familiar with as this means having to bear the unknown risk of design failure. Resistance to change from customary practices and solutions indicates a risk averse behavior which could threaten the project's interest.

"When consultants are hired, and the project managers don't manage the process well, all sorts of crap comes in and usually stuff that's been used over 20 years gets into the system and that's why you build the same way you built 20 years back. Because you have to make that change to enable this sort of, good initiatives to further through the system, and that's not happening right now" (CE04).

"I think, some of the engineers that we have worked with they are quite comfortable where they are going and whatever they have been doing. There is one project, two different projects that the M\&E engineers are the same. The layout that they provide us is very similar, up to the point we asked is this a cut and paste project of the other" (G04).

Despite governed by professional ethics which include a duty of care to the client, many engineers do not make decisions based on what is best for the client, but rather what is convenient for them at the time of design. The energy efficiency performance of the building does not affect the design liabilities of the Engineer unless the contract was performance based. Hence, the priority of the Engineer in when specifying the air conditioning system was to ensure it was cool at the time it was being commissioned.

Overcooling is a situation that occurs during building operation, which is beyond the liability of the engineer and thus, unless the contract specified it under his work scope, he was not obliged to ensure the building did not run inefficiently.

"He doesn't really care how much the cooling system costs. And he also doesn't care how efficiently it runs once the building operates because that's a few months in the end" (ME08).

While many engineers are aware of the importance of green buildings, not many are able to design for it. It requires extensive technical knowledge in green design and energy efficient systems especially for the design consultants who specify what goes into the building. This knowledge competency goes beyond the normal expectation of design consultants. In specifying the building cooling system, the mechanical engineer would need to be informed of the available systems in the market and the make the necessary calculations to justify the appropriate cooling load.

"Definitely for green buildings it involves more technical knowledge especially for the design consultants like the Architect and M\&E engineer because they have to know a lot of systems which actually talk about energy saving" (A05).

In the haste to develop the country as soon as possible, many buildings are designed with little consideration of the environmental effects. Often this is because the detrimental effects of building construction to the environment are not obvious until a very long time. 
Thus, the need to commit to sustainable solutions do not seem urgent at present time. A long time is required to build knowledge through research data and awareness growth so that building designers are informed of the effects from every design solution they decide upon.

"Because we wanted to develop our country so fast, we overlook all the effects of construction. Overlook in a sense that time does not permit enough knowledge about the environmental (effects) because these studies always take a long time to predict what's going to happen in the future because of our construction today... you need to do testing, you have to have research data to tell you, 'Okay look, if you do this, this may happen. If you do that, this may happen'"(A02).

\section{Bigger is Better Mentality}

$72 \%$ of interviewees said that air conditioners were often specified bigger than the minimum necessary size per building cooling load. Many engineers prefer to play it safe by increasing the necessary cooling load of the building by a margin as a safety measure to ensure that the air conditioning system specified will be cool enough in case the cooling load increases in future. This is also identified as a risk averse behavior.

"Get a bigger chiller because then you will always have plenty of cooling" (ME04).

One interviewee likened the situation to a person going on a hiking trip where someone else had packed his backpack for him with too many things he did not need. Thus, the backpack becomes unnecessarily costly and heavy, which causes the hiker to be inefficient due to the overloading weight.

"Therefore, he ends up paying too much for this backpack and then once he starts walking, he's also not very energy efficient. So, it's like, almost like a double penalty" (G03).

Building specifications also depend on the interest of the project developer. When the building is built for sale to other users, energy efficiency during the building operation would not be the main interest of the developer but rather the capital cost of the project takes precedence. This is because the benefits of energy efficiency are long term and only directly affect building owners who will pay for the building operation expenses. In result, the cooling system specified is often not downsized to the appropriate energy efficiency level. The fragmented work nature of design consultants also contributes to the problem of over-specification. In many cases, the passive and active design solutions are decided independent of each other. Specification of active design solutions often do not take into consideration the architectural design solutions already implemented, which could have already brought the building cooling load down so that the air conditioner could be downsized.

"Often, we end up with a cooling system that's either not downsized at all, or maybe downsized toward where it should be but not down where it ought to be. So then of course, then you have additional cost on the green... you've already done your energy efficient features, you paid a little bit more for the light, for the glazing. But then you don't reap the benefits of getting a cheaper cooling system" (CE04).

Fee Structure

$38 \%$ of interviewees shared the dilemma of most projects to downsize mechanical works due to its direct correlation to the mechanical engineer's fee. As the fee structure depends on the price of active design solutions required, downsizing the solutions would also mean downsizing the necessary fee. By right, the mechanical engineering fee should not be compromised by the value of mechanical works because they are regulated by a scale of fees from the Board of Engineers Malaysia (BEM). However, this is not habitually practiced in 
the Malaysian building industry as 'discounts' have become the norm.

"Yeah. And I think in some countries this problem is even compounded because of the fee of let's say, mechanical engineers. It's a certain percentage of the mechanical cost. So, when we come in and say, okay you can half your cooling system, then we're also halving his fee" (G01).

"It's like a direct incentive to not go green" (ME08). Improper Testing and Commissioning

Testing and commissioning is a fundamental activity at the end of every building project where all systems are tested and commissioned accordingly to ensure they work. $64 \%$ of interviewees agreed that the testing and commissioning exercise would be better outsourced to a third party to enable a more rigorous practice that included checking energy efficiency levels. The usual practice is for the design consultants to perform testing and commissioning themselves as part of their contracted work scope. The interviewees felt that a third party could benefit the project by providing relevant comments on how to improve the building energy index. This exercise would prevent the problem of overspecification as energy performance levels are reviewed before accepting a system. However, while this will certainly add value to the project, the interviewees felt that it can be difficult to implement in actual practice as it can lead to conflict. It is difficult to convince project engineers to agree to this idea because they assume having a third party to do the testing and commissioning is similar to having someone questioning their credibility in design. Engineers become defensive as if being interrogated for their work.

"For some projects we really have trouble convincing them, they actually don't want a commissioning specialist because they are going along the line why do you need somebody to vet our design?" (G04).

This becomes increasingly difficult because the Malaysia building standards do not set a requirement on the energy efficiency level to achieve. While standards and guidelines for energy efficient building designs are available, it has not been imposed as a statutory obligation. One interviewee suggested imposing fines on projects for not achieving a desirable energy efficiency level required by the local authorities. The interviewees also raised concern that there is an increasing need to enforce the Malaysian Standard 1525 Energy Efficiency guideline on building standard regulations.

"The local authorities should put an energy benchmark for all building projects to achieve. And say, if you don't achieve the minimum benchmark, you get fined a certain amount. The lower you achieve from the benchmark, the higher the fines you need to pay".

TABLE 1 . Analysis of decision choice

\begin{tabular}{lll}
\hline \hline Causes & Rationale & Decision Choice \\
\hline Quick solution & Confidence in tried solutions & - Follow past solutions \\
& & - Use rule of thumb \\
\hline Resistance & Avoid risk of system failure; & - Reject new solutions \\
& Reduce liability; & - Specify an effective cooling system \\
& Lack information on energy efficient technology & - Use familiar systems \\
\hline Bigger is better mentality & Avoid risk of insufficient cooling & - Specify bigger air conditioning \\
Fee structure & Desire higher fees & - Design bigger mechanical works \\
\hline Improper testing and commissioning & Defend credibility & - Resist third party commissioning specialist \\
\hline \hline
\end{tabular}

\section{DISCUSSION}

The paper has demonstrated the problems of over-specification in green building projects that inhibit energy efficiency in the building performance. These problems occasioned 
from five underlying causes of over-specification, which are all pertinent to decision choices of the design consultant team. In this section, findings of the study are discussed using the rational choice theory to explain the decision choice of construction actors. Table 1 presents the analysis of decision choices made from the five causes identified.

The analysis adopts the discrete purposeful actor assumption of the rational choice theory, which believes that human beings are consciously aware of their courses of action and considers them before making a decision. It confirms that every decision choice is supported by a logical explanation for the decision-maker (Lovett, 2006). As shown in Table 1, decision choices for determining the air conditioning system in office buildings typically reiterate the human thought process.

It also demonstrates the application of heuristics where decision-makers imitate the same decision choices made in the past for similar situations as a quick and effective solution (Cherry, 2014). Design consultants were found to make decisions choices in consideration of the effects of that decision to themselves, which often does not result to the most optimal option for the project. Consistent with Sorrell (2003) and Chai and Catrina, (2012) consultants tend to avoid risk and reduce liability for themselves by specifying only systems they know that effectively work at a size that could cater for the existing cooling load as well as possible future upgrades.

The linear work pattern of consultants produced a detached work environment where consultants perform tasks in isolation of one another and therefore lack an overview understanding of the project design. Thus, critical design solutions are decided within the limits of the consultant's knowledge. The finding supports the study by Lovins (1992) and Chai and Catrina, (2012) who also discovered that specifications were decided based on incomplete information of the building's design. Actors would show resistance to solutions and practices that threatened their liability and imposed new risks, and maintain preference for familiar systems within their knowledge.

While previous scholars have yielded similar results, the research context was entirely different. The literature revealed no studies conducted in a construction project setting to explain the overcooling problem in office buildings that surfaced from design decisions. The evidence shows that the decision choice of construction actors are in keeping with the rational choice theory and can be explained through five main causal explanations.

\section{CONCLUSION AND RECOMMENDATIONS}

The findings show that over-specification of cooling systems can lead to the overcooling problem in office spaces. As office buildings commonly use centralized air conditioners, the right specification is important to ensure a comfortable indoor climate. It was evident that many interviewees shared similar experiences where larger than necessary air conditioning systems were being specified for low cooling loads. The problem can be explained by the practice of quick solutions, resistance from design consultants, a 'bigger is better' mentality, unsupportive fee structures, and poor testing and commissioning practices. The results inform a need for review in the way active designs are specified as some mis-alignment between active and passive design considerations is apparent. The highest contributing factor is the resistance from design consultants to change and consider new solutions that break away from customary practices. It was also found that there was a need for review in the fee structure for mechanical engineers to encourage sustainable solutions. Procedures for testing and commissioning need to be revisited to allow opportunities for energy efficiency improvements. The research findings provide useful infor- 
mation to policy makers regarding the overcooling phenomenon in Malaysia and highlight the importance of energy efficient regulations to be imposed. Further research is needed to overcome the causes of overcooling phenomenon and abetting policy makers in alleviating overcooling risk as well as ensuring energy efficient building designs.

\section{ACKNOWLEDGEMENT}

We sincerely acknowledge the financial support provided by the University of Heriot-Watt, Malaysia and the Malaysian Government through the MyBrain 15 scholarship as well as the physical support by the Universiti Sains Malaysia (USM) for this research.

\section{REFERENCES}

Abbaszadeh, Sahar, Leah Zagreus, David Lehrer, and Charlie Huizenga. 2006. Occupant satisfaction with indoor environmental quality in green buildings. Paper presented at the Proceedings of Healthy Buildings, International Society of Indoor Air Quality and Climate, Lisbon, PT.

Ahmad, Nur Azfahani, and Abd Aziz Abdul-Ghani. 2011. Towards sustainable development in Malaysia: In the perspective of energy security for buildings. Procedia Engineering 20, 222-229. DOI: 10.1016/j.proeng.2011.11.159

Albadi, Mohamed H., and Ehab El-Saadany. 2008. A summary of demand response in electricity markets. Electric Power Systems Research 78, no. 11: 1989-1996. D0I: 10.1016/j.epsr.2008.04.002

Alyami, Saleh H., and Yacine Rezguib. 2012. Sustainable building assessment tool development approach. Sustainable Cities and Society 5, no. 0: 52-62. DOI: 10.1016/j.scs.2012.05.004

Ardyanfitri, Helmina, and Ratri Wahyuningtyas. 2016. The influence of job career development opportunities, training, occupational safety and health on the job satisfaction of employees in the Telkom University. Journal of Administrative and Business Studies 2, no. 5: 231-240. DOI: 10.20474/jabs-2.5.3

Ary, Donald, Lucy Cheser J., Christine K. Sorensen I., and David Walker. 2013. Introduction to research in education. Boston, MA: Cengage Learning.

Baker, Nick, and Koen Steemers. 2003. Energy and environment in architecture: A technical design guide. London, UK: E\&FN Spon.

Boshoff, Tinus. 2016. Managing office temperature. URL: https://goo.gl/TBfBB2 (accessed December 21, 2016).

Boudon, Raymond. 2009. Rational choice theory. Social theory. In the new blackwell campaign to social theory, ed. Bryan S. Turner. Chichester, UK: Wiley-Blackwell.

Bryman, Alan. 2008. Of methods and methodology. Qualitative Research in Organizations and Management: An International Journal 3, no. 2: 159-168. DOI: 10.1108/17465640810900568

Chai, Kah-Hin, and Catrina Yeo. 2012. Overcoming energy efficiency barriers through systems approach-A conceptual frame- $\quad$ work. Energy Policy 46, 460-472. DOI: 10.1016/j.enpol.2012.04.012

Cherry, Kendra. 2014. What is a heuristic and how does it work? URL: https://goo.gl/RLdrcC (accessed May 16, 2014). Chua, Shirley JL., Azlan Shah A., and Melissa Ee Ling L. 2016. Physical environment comfort impacts on office employee's performance. Paper presented at the MATEC Web of Conferences, Les Ulis, FR.

DOI: $10.1051 /$ matecconf/20166600124

Creswell, John W. 2012. Qualitative inquiry and research design: Choosing among five approaches. 3rd ed. California, CA: Sage Publications.

de Dear, Richard, and Marc E. Fountain. 1994. Field experiments on occupant comfort and office thermal environments in a hot-humid climate. URL: https://goo.gl/r4pBzg (accessed January 01, 1994).

El-Ghalayini, Yousif. 2016. The effects of high performance work system on employee attitudes: A study of international organization. Journal of Administrative and Business Studies, 2, no. 5: 248-263. D0I: 10.20474/jabs-2.5.5

Flick, Uwe. 2014. An introduction to qualitative research. 5th ed. London, UK: Sage Publications Ltd.

Huizenga, Charlie, Sahar Abbaszadeh, Leah Zagreus, and Edward Arens. 2006. Air quality and thermal comfort in office buildings. Results of a large indoor environmental quality survey. Paper presented at the Proceedings. Healthv 
Build- ings, International Society of Indoor Air Quality and Climate, Lisbon, PT.

Kosonen, Risto, and F. Tan. 2004. Assessment of productivity loss in air-conditioned buildings using PMV index. Energy and Buildings 36, no. 10: 987-993. DOI: 10.1016/j.enbuild.2004.06.021

Lan, Li, Pawel Wargocki, and Zhiwei Lian. 2011a. Quantitative measurement of productivity loss due to thermal discomfort. Energy and Buildings 43, no. 5: 1057-1062. D0I: 10.1016/j.enbuild.2010.09.001

Lan, Li, Pawel Wargocki, David P. Wyon, and Lian, Z. 2011b. Effects of thermal discomfort in an office on perceived air quality, SBS symptoms, physiological responses, and human performance. Indoor Air 21, no. 5: 376-390.

DOI: $10.1111 / \mathrm{j} .1600-0668.2011 .00714 . x$

Lincoln, Yvonna S., and Egon G. Guba. 1985. Naturalistic inquiry. New York, NY: Sage Publications.

DOI: $10.1016 / 0147-1767(85) 90062-8$

Lindner, Marcus, Michael Maroschek, Sigrid Netherer, Antoine Kremer, Anna Barbati, Jordi Garcia-Gonzalo, Rupert Seidi, Sylvain Delzon, Piermaria Corona, Marja Kolstrom, Manfred J. Lexer, and Marco Marchett. 2010. Climate change impacts, adaptive capacity, and vulnerability of European forest ecosystems. Forest Ecology and Management 259, no. 4: 698-709. DOI: 10.1016/j.foreco.2009.09.023

Lovett, Frank. 2006. Rational choice theory and explanation. Rationality and Society 18, no. 2: 237-272.

DOI: 10.1177/1043463106060155 Lovins, Amory. 1992. Energy-efficient buildings: Institutional barriers and opportunities. URL: https://goo.gl/OBE3vn (accessed December 31, 1992).

Luber, George, and Michael McGeehin. 2008, Climate change and extreme heat events. American Journal of Preventive Medicine 35, no. 5: 429-435. DOI: 10.1016/j.amepre.2008.08.021

McSweeney, Robert. 2015. Hydrofluorocarbon emissions up 54\% with air conditioning on the rise. URL: https://goo.gl/dpjC8C (accessed April 27, 2015).

National Institute of Building Sciences (NIBS). 2008. Assessment to the US congress and US department of energy on high performance buildings. URL: https://goo.gl/EjOD3a (accessed December 14, 2008).

Ng, Ban-Huat, and Zainal Abidin A. 2013. Post occupancy evaluation of energy-efficient buildings in tropical climates-Malaysia'. ArchNet-IJAR 7, no. 2: 8-21.

Omer, Abdeen M. 2008. Energy, environment and sustainable development. Renewable and Sustainable Energy Reviews 12, no, 9: 2265-2300. DOI: 10.1016/j.rser.2007.05.001

OSHREP. 2016. Offices: Temperature and humidity-What are the 'rules'?

URL: https://goo.gl/T5CLQs (accessed June 12, 2016).

Sorrell, Steve. 2003. Making the link: Climate policy and the reform of the UK construction industry. Energy Policy 31, no. 9: 865-878. DOI: 10.1016/S0301-4215(02)00130-1

Suziyana, Mat Dahan, Nina Suhaity A., Mohd Yusof T., and Ahmad Basirul SBA. 2013. Analysis of heat gain in computer lab- oratory and excellent centre by using CLTD/CLF/SCL method. Procedia Engineering 53: 655-664.

DOI: $10.1016 /$ j.proeng.2013.02.085

Tisdell, Clem. 2008. Global warming and the future of Pacific Island countries. International Journal of Social Economics 35, no. 12: 889-903. DOI: 10.1108/03068290810911444

United Nations Development Programme (UNDP). 2009. Promoting energy efficiency in buildings: Lessons learned from international experience. URL: https://goo.gl/d2ao4B (accessed March 12, 2009).

Wang, Xiaoming, Dong Chen, and Zhengen Ren. 2010. Assessment of climate change impact on residential building heating and cooling energy requirement in Australia. Building and Environment 45, no: 7: 1663-1682.

DOI: $10.1016 /$ j.buildenv.2010.01.022

Zhang, Heng, and Siu Lai Lei. 2013. Assessing the renovation of existing residential buildings regarding environmental effi- $\quad$ ciency. Asian Journal of Environment-Behaviour Studies 4, no. 14: 19-36. 